\title{
Temporal and spatial variation of NPP and its response to climatic factors in main river valleys on the southern slope of Qilian Mountains
}

\author{
YANG Rong-rong ${ }^{1,2,3}$, CAO Guang-chao ${ }^{1,2,3, *}$, CAO Sheng-kui ${ }^{1,2,3}$, LAN Yao ${ }^{1,2,3}$, ZHANG Zhuo ${ }^{1,2,3}$, CHEN Zhi-rong ${ }^{1,2,3}$ \\ CHEN Zhen ${ }^{1,2,3}$ \\ ${ }^{1}$ College of Geographical Science, Qinghai Normal University, Xining 810008, China \\ ${ }^{2}$ MOE Key Laboratory of Tibetan Plateau Land Surface Processes and Ecological Conservation, Xining 810008, China \\ ${ }^{3}$ Key Laboratory of Qinghai Province Physical Geography and Environmental Processes, Xining 810008, China
}

\begin{abstract}
Based on the NPP products of MODIS data, the spatial and temporal distribution characteristics of grassland NPP and its response to climatic factors in the vegetation growing season of the main river valleys in the southern slope of Qilian Mountains from 2000 to 2016 were carried out by correlation analysis and spatial interpolation. The research further provides a scientific basis for the quality evaluation of grassland ecosystems on the southern slope of Qilian Mountain and the rational use of grassland resources along the river. The results show that: (1) With the increasing distance of buffers on both sides of the river, the NPP of grassland in each year shows the characteristics of "single-peak" distribution, which is increased first and then decreased; (2) the NPP of grassland in the main river valley of the southern slope of Qilian Mountain The spatial distribution characteristics show a trend of increasing from northwest to southeast. (3) The spatial distribution of NPP and air temperature in the main river valleys of the southern slope of Qilian Mountains is gradually increasing from northwest to southeast, but the spatial distribution correlation coefficient of NPP and precipitation in the river valley grassland of vegetation growing season basically shows a trendof decreasing from northwest to southeast.
\end{abstract}

\section{Introduction}

Terrestrial ecosystems are important places for human production and life, and vegetation is an indispensable part of terrestrial ecosystems. In view of this, studying the health status of terrestrial ecosystem vegetation and the strength of production capacity is of great significance to human ${ }^{[1-2]}$. Net Primary Production (NPP) refers to the amount of organic matter accumulated by green plants per unit time and unit area. Net primary production (NPP) refers to the amount of organic matter accumulated by green plants per unit time and unit area. It is the total amount of organic matter produced by photosynthesis (Gross Primary Productivity, GPP) minus the remainder of autotrophic respiration (RA) consumption ${ }^{[3]}$.

Foreign scholars have studied the NPP earlier, and mainly stayed at applying various models for estimation. On the basis of foreign scholars' research, domestic scholars gradually improved and widely applied the model. For example, scholars from Germany, India, and the United States have created models based on climate and remote sensing data, and calculated NPP in tropical rainforests, India, and global scales in South America, and analyzed their correlations with climatic factors ${ }^{[4-6]}$. Based on the light energy utilization model, Zhou Xiafei,
Tian Zhihui and Yan Junjie use the NPP data from remote sensing data MOD17A3 as the data source to measure the NPP of the Tibet Plateau, the Yellow River Basin and the Yili River Valley, and analyze their temporal and spatial variation characteristics and influencing factors ${ }^{[7-9]}$. At the same time, Zhao Ting, Gang Chengcheng, Li Gang and other scholars study the spatial and temporal distribution of grassland NPP and the response to climate factors in the world and parts of the region [10-12]. Vegetation NPP is widely used in various vegetation types as a production capacity reflecting certain land use types, and it is widely used in the research of grassland NPP [1314]. For example, domestic scholars Yang Wei, Zhou Ping, and Zhang Meiling study the distribution of grassland NPP and its influencing factors in different provinces of China, and analyze the differences between different types of grassland NPP ${ }^{[15-17]}$.

At present, domestic and foreign scholars have studied the spatial and temporal distribution of NPP of grassland vegetation and its influencing factors, but the research on NPP in river valley grassland has rarely been reported ${ }^{[18]}$. In the light of this, based on MODIS data, the temporal and spatial distribution of grassland NPP and its response to climatic factors are studied in the main river valleys of the southern slope of Qilian Mountains. This further provides a data method for the dynamic monitoring of 
grassland in the main river valley, and makes a due contribution to the protection of grassland resources and ecological environment on the southern slope of Qilian Mountain.

\section{Overview of the Study Area}

The southern slope of Qilian Mountain lies on the northeastern edge of the Tibet Plateau. It is located in the transitional zone between the Loess Plateau and the Tibet Plateau, combining the characteristics of the both two plateaus. The geographical location of the study area is $98^{\circ} 08^{\prime} 13^{\prime \prime} \sim 102^{\circ} 38^{\prime} 16^{\prime} \mathrm{E}, 37^{\circ} 03^{\prime} 17^{\prime \prime} \sim 39^{\circ} 05^{\prime} 56^{\prime \prime} \mathrm{N}$, the total area is about $2.4 \times 10^{4} \mathrm{~km}^{2}$, and the altitude range is $2257 \sim 5235 \mathrm{~m}$. It is long and cold in winter, and the summer is short and cool. The annual average precipitation is around $400 \mathrm{~mm}$, and the annual average temperature is $-5.9^{\circ} \mathrm{C}$. The surface runoff of the southern slope of Qilian Mountain is abundant, since the rivers of Heihe, Datong, Tuole and Babao rivers run through the whole research area from northwest to southeast. The vegetation types in the study area are mainly grassland.

\section{Data Sources and Methods}

\subsection{Grassland NPP acquisition principle ${ }^{[19]}$$$
N P P=G P P-R_{m}-R_{g} \quad(1)
$$$$
R_{g}=0.25 \times N P P \quad(2)
$$

In the equation, NPP represents the net primary productivity of vegetation, GPP represents the total primary productivity of vegetation, $\mathrm{Rm}$ is the vegetation to maintain the respiration, and $\mathrm{Rg}$ is the vegetation growth respiration.

\subsection{Data sources and pre-processing}

The Moderate-resolution Imaging Spectroradiometer (MODIS) is a large-scale space remote sensing instrument developed by NASA to understand global climate change and the impact of human activities on climate. It provides long-term continuous observation of the lithosphere, biosphere and atmosphere of the Earth's surface [20].

The NPP data studied in the article is derived from the MOD17A2H data product on the NASA website(https://ladsweb.modaps.eosdis.nasa.gov). The row and column numbers are $25 \mathrm{v}$ and $26 \mathrm{v}$, the spatial resolution is $500 \mathrm{~m}$, and the time resolution is $8 \mathrm{~d}$. The NPP data is inlaid by the Arc GIS 10.2 software platform, and the format conversion is performed. The conversion factor is 0.1 . The NPP of the vegetation growing season is obtained through a series of calculations and accumulations, and the unit is $\mathrm{gC} \cdot \mathrm{m}^{-2}$. Finally, through the projection and resampling of NPP data, and using the vector file of the main river valley grassland on the southern slope of Qilian Mountain, the NPP data of the grassland in the study area is obtained. Besides, the meteorological data comes from the China Meteorological Data Network (https://data.cma.cn), including temperature and precipitation data observed by 39 meteorological stations in Qinghai Province. Eventually, through spatial interpolation and other processing, and using the vector file of the main river valley grassland on the southern slope of Qilian Mountain, the temperature and precipitation data of the river valley in the study area are obtained.

\subsection{Selection of rivers and determination of buffer zones}

Since ancient times, rivers have been closely related to human civilization and are the source and birthplace of human civilization. Within a certain range on both sides of the river, there are areas where human activities are more frequent and concentrated, and areas where vegetation changes are more sensitive. Since that, the study of grassland NPP in the buffer growing season on both sides of the main river on the southern slope of Qilian Mountain is carried out, which has great significance for the dynamic monitoring of grassland growth on both sides of the river in the study area. It is known that Heihe River, Babao River, Tuole River and Datong River run through the entire southern slope of Qilian Mountain in parallel. Therefore, the main river on the southern slope of Qilian Mountain is taken as the baseline with $0.5 \mathrm{~km}$ as the unit buffer distance and $8 \mathrm{~km}$ as the largest influence range on both sides of the river. The scope of influence is divided into 16 buffer stages in order to study the spatial distribution and correlation of grassland NPP in the vegetation growing season of each buffer.

\subsection{Research methods}

Using the ArcGIS 10.2 software platform, the annual average NPP of the grassland in the main river buffer zone on the southern slope of Qilian Mountain is obtained, and recorded as xi $(i=1,2,3, \ldots n)$. Further, the SPSS 21 software platform is used to analyze the correlation between the annual average NPP of grassland in the buffer zone and temperature and precipitation. The correlation coefficient is calculated as follows ${ }^{[21]}$ :

$$
\begin{gathered}
R_{x y}=\frac{\sum_{i=1}^{n}\left(x_{i}-\bar{x}\right)\left(y_{i}-\bar{y}\right)}{\sqrt{\sum_{i=1}^{n}\left(x_{i}-\bar{x}\right)^{2} \cdot \sum_{i=1}^{n}\left(y_{i}-\bar{y}\right)^{2}}} \\
R_{x z}=\frac{\sum_{i=1}^{n}\left(x_{i}-\bar{x}\right)\left(y_{i}-\bar{y}\right)}{\sqrt{\sum_{i=1}^{n}\left(x_{i}-\bar{x}\right)^{2} \cdot \sum_{i=1}^{n}\left(y_{i}-\bar{y}\right)^{2}}}
\end{gathered}
$$

In the equation, $R_{x y}$ and $R_{x z}$ represent the correlation coefficient between NPP and temperature and precipitation in each buffer; $i$ represents the year; $x i$ represents the NPP value of the $i$-th year; $y_{i}$ represents the temperature value of the $\mathrm{i}$-th year; $\mathrm{z}_{\mathrm{i}}$ represents the precipitation value of the $\mathrm{i}$-th year; $\bar{x}$ represents the average value of NPP for each year; $\bar{y}$ represents the average temperature of each year; $\bar{z}$ represents the average value of precipitation for each year. An absolute value of $\mathrm{R}$ larger than 0.8 indicates a high correlation between the two; an absolute value of $\mathrm{R}$ larger than 0.3 and less than 0.8 indicates a general correlation between 
the two; an absolute value of $\mathrm{R}$ less than 0.3 indicates a low correlation between the two.

Based on the thin-strip spline function method, this paper uses DEM as a covariate to import the latitude and longitude coordinates of Qinghai Province into ArcGIS 10.2, extracts the elevation from the DEM using the Extract values to point tool in the toolbox, and perform the projection transformation. Then, the attribute table is exported and saved as the format required for the spatial interpolation of the thin-spline spline function for interpolation. Finally, the spatial distribution of temperature and precipitation in the study area is obtained.

\section{Results and Analysis}

\subsection{Temporal and spatial distribution of NPP in vegetation growing season in main river valleys of southern slope of Qilian Mountains}

The spatial and temporal distribution characteristics of NPP in the buffer zones of the main river valleys on the southern slope of the Qilian Mountains from 2000 to 2016 are shown in Fig. 1. The figure shows that with the increasing distance of the buffers on both sides of the river, the NPP of the grassland in each year shows the unimodal distribution characteristics of the first rise and then fall, and the change trend is basically the same. In the range of $0 \sim 2.5 \mathrm{~km}$ from the river, with the increase of the buffer distance, the NPP value gradually increases, and the range is between $178.66 \sim 241.61 \mathrm{gC} \cdot \mathrm{m}^{-2}$. In this distance interval, the NPP of the river valley is positively correlated with the distance. In the range of $2 \sim 2.5 \mathrm{~km}$ from the river, the NPP value reaches the maximum. In the range of $2.5 \sim 8 \mathrm{~km}$ from the river, the NPP value decreases gradually with the increase of the buffer distance, and the range is between 173.42 241.61 gC·m-2. In this distance interval, the NPP of the river valley is negatively correlated with the distance.

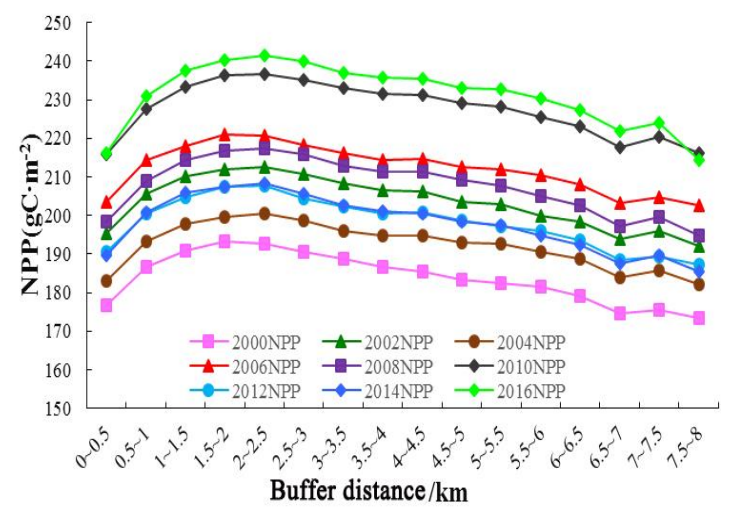

Figure 1 Temporal and spatial distribution of NPP in grassland in the main river valleys of the southern slope of Qilian Mountains from 2000 to 2016

From 2000 to 2016, the NPP values of the main river valleys on the southern slope of Qilian Mountain were between 173.42 and $241.61 \mathrm{gC} \cdot \mathrm{m}^{-2}$. In 2000 , the NPP values of the buffer zones in the river valley were lower than those of other years, while the NPP values of the buffer zones in the river valley in 2016 were much higher than other years. And the NPP values of other years are lower or higher than the NPP value of a certain year in each buffer range. It can be inferred that since the implementation of the policy of returning farmland to forests and grasslands in 2000, the counties within the southern slope of Qilian Mountain have achieved remarkable results. Given this, the NPP changes in grassland in the main river valleys of the southern slope of Qilian Mountains from 2000 to 2016 may be affected by human factors more than natural factors.

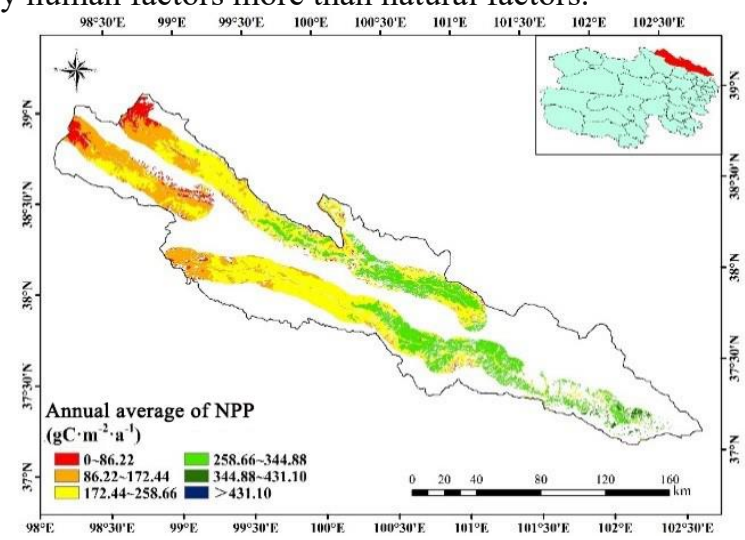

Figure 2 Spatial distribution of grassland NPP in the main river valleys of the southern slope of Qilian Mountains from 2000 to 2016

The spatial distribution of NPP in the main growing valleys of the southern slope of the Qilian Mountains is gradually increasing from northwest to southeast, as shown in Figure 2. Among them, the low-value area $\left(0 \sim 172.44 \mathrm{gC} \cdot \mathrm{m}^{-2} \cdot \mathrm{a}^{-1}\right)$ is mainly distributed in Yanglong and Yeniugou of Qilian County, which is the northwest part of the study area, accounting for $30.06 \%$ of the total study area. The median area $\left(172.44 \sim 344.88 \mathrm{gC} \cdot \mathrm{m}^{-2} \cdot \mathrm{a}^{-1}\right)$ is mainly distributed in some areas of Zamashi, Arou, Ebao Town, Mole and Menyuan in Qilian County, accounting for $69.12 \%$ of the total study area. The high value area $\left(>344.88 \mathrm{gC} \cdot \mathrm{m}^{-2} \cdot \mathrm{a}^{-1}\right)$ is mainly distributed in Huangcheng Mongol Ethnic Township, Xianmi and Zhugu of Menyuan County, accounting for $0.82 \%$ of the total study area.

\subsection{Annual average NPP response to climatic factors in main river valleys of the southern slope of Qilian Mountains}

This paper uses correlation analysis method to analyze the annual average NPP response to climate factors in the main river valleys of the southern slope of Qilian Mountains. The results show that the spatial distribution of NPP and temperature and precipitation correlation coefficients in the main river valleys of the study area is obvious, and the spatial distribution difference has both positive and negative correlation. 


\subsubsection{Annual average NPP response to temperature in grassland}

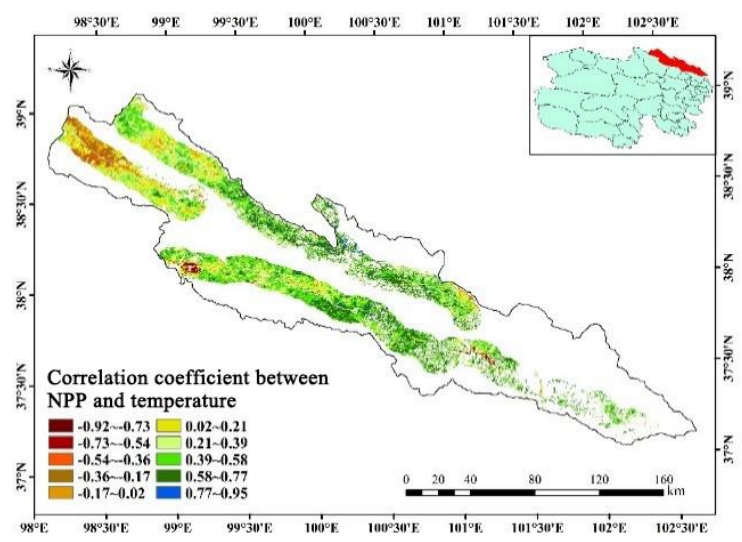

Figure 3 Spatial distribution of correlation coefficient between NPP and air temperature in main river valleys of the southern slope of Qilian Mountains from 2000 to 2016

The correlation between annual average NPP and temperature in the main river valleys of the southern slope of Qilian Mountains is positively correlated with most regions, and some regions have negative correlations, as shown in Figure 3. Among them, the area with less correlation $(\mathrm{R}<0.3)$ accounted for $19.03 \%$ of the entire study area; the medium relationship $(0.3 \leq \mathrm{R} \leq 0.8)$, accounting for $79.94 \%$; the area with a large correlation $(\mathrm{R}>0.8)$ accounted for $1.03 \%$. The upper reaches of the Tuole River, the main river of Qilian Mountain, is located near the Yanglong of Qilian County. The annual average NPP of the grassland there has a negative correlation with the temperature. There is a positive correlation between the annual average NPP and temperature in the river valleys near Yeniugou in Qilian County and Muli in Tianjun County, but the correlation is not significant. There is a positive correlation between the NPP and the temperature in the river valleys near Zamashi, Arou, Ebao and Mole in Qilian County, and the correlation is significant.

\subsubsection{Annual average NPP response to precipitation in grassland}

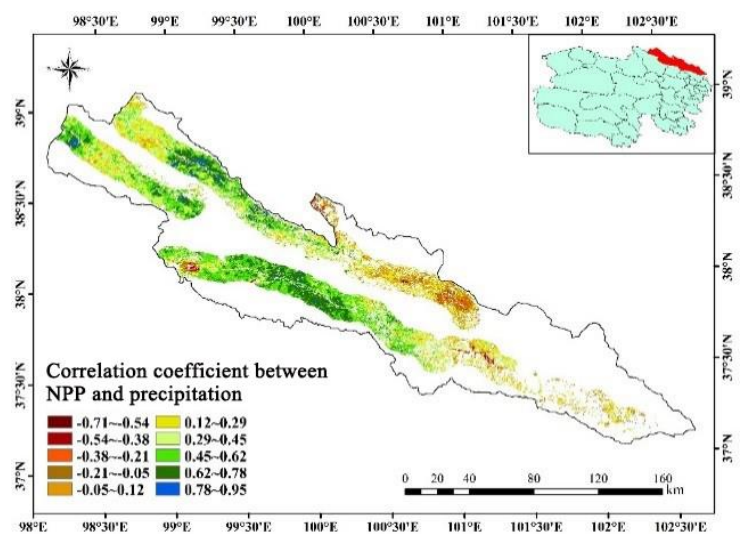

Figure 4 Spatial distribution of correlation coefficient between NPP and precipitation in main river valleys of the southern slope of Qilian Mountains from 2000 to 2016
The correlation between annual average NPP and precipitation in the main river valleys of the southern slope of Qilian Mountains is positively correlated with most regions, and some regions have negative correlations, as shown in Figure 4. Among them, the area with less correlation $(\mathrm{R}<0.3)$ accounted for $31.26 \%$ of the entire study area; the area with moderate correlation $(0.3 \leq \mathrm{R} \leq$ 0.8 ), accounting for $67.13 \%$; the area with a large correlation $(\mathrm{R}>0.8)$ accounted for $1.61 \%$. The main river valleys of Qilian Mountain are located in the vicinity of Zamashi, Arou and Ebao in Qilian County and in the Menyuan Hui Autonomous County. The annual average NPP in these river valleys is negatively correlated with precipitation. There is a positive correlation between the annual average NPP and precipitation in the river valley near the Yanglong of Qilian County, but the correlation is not significant. There is a positive correlation between the NPP and the temperature of the grassland along the rivers from Yeniugou of Qilian County, the Muli of Tianjun County to Mole of Qilian County, and the correlation is significant.

\section{Discussion}

Based on the NPP products of MODIS data, this paper studies the spatial and temporal distribution of NPP in the main river valleys of the southern slope of Qilian Mountains and its response to climatic factors, and compares the research results with the domestic scholars.

With the increasing distance of buffers on both sides of the river, the NPP of the main river valleys on the southern slope of Qilian Mountain in 2000-2016 showed the characteristics of unimodal distribution with increasing first and then decreasing, which is basically consistent with the buffer interval of the maximum peak distribution. This result is basically in accordance with the analysis of domestic scholars such as Lin Zhidong ${ }^{[22]}$ on NPP in the Junxi Valley of Datian County. What's more, the peak value of NPP is in the buffer zone of $1.5 \sim 2.5 \mathrm{~km}$. In this study, the peak value of NPP is in the buffer zone of $2 \sim 2.5 \mathrm{~km}$, which is included in the buffer range of $1.5 \sim 2.5 \mathrm{~km}$, indicating that the results of this study are proven to be rational.

From 2000 to 2016, the spatial distribution of NPP in the main growing valleys of the southern slope of the Qilian Mountains was generally characterized by low northwest and high southeast. This result is in line with the analysis of the research on the net primary productivity of the vegetation in the Shule River Basin by Pan Jinghu et al. This is closely related to the spatial variation of altitude in the region, that is, the NPP gradually decreases as the altitude increases. Domestic scholar Li Suying ${ }^{[23]}$ studies the ecological impact of terrain on NPP in typical steppe areas. Her results show that NPP gradually increases with increasing altitude, which is obviously contrary to the conclusion of this study. In the range of $2257 \sim 5235 \mathrm{~m}$ above sea level, NPP shows a decreasing trend with the increase of altitude. In the range of $828 \sim 1681 \mathrm{~m}$ above sea level, NPP basically shows an increasing trend with the increase of altitude. This is mainly due to the difference in the altitude range of the 
two study areas, and the high value area of vegetation NPP may be at an altitude of about $2000 \mathrm{~m}$, which is more suitable for the growth and development of vegetation.

From 2000 to 2016, the spatial distribution of the correlation coefficient between NPP and temperature and precipitation in the main growing valley of the southern slope of the Qilian Mountains was gradually increasing and decreasing from northwest to southeast. However, some areas are positively correlated and some are negatively correlated. This result is similar to the results obtained by Zhang Yushun et al. ${ }^{[24]}$ scholars in response to the climatic factors of Qilian Mountain's net primary productivity in the past 11 years, while the results of the research on the net primary productivity of vegetation on the Loess Plateau are inconsistent with those of Shi Xiaoliang et al. ${ }^{[25]}$ This may be due to the fact that the Qilian Mountains are located on the Qinghai-Tibet Plateau, and the terrain is complex and diverse. There are close relationships between the microclimates formed in the mountains.

\section{Conclusion}

Based on the NPP products of MODIS data, this paper studies the spatial and temporal distribution of NPP in the main river valleys of the southern slope of Qilian Mountains and its response to climatic factors, and draws the following conclusions:

(1) With the increasing distance of buffers on both sides of the river, the NPP of the main river valleys on the southern slope of Qilian Mountain in 2000-2016 shows the characteristics of unimodal distribution with increasing first and then decreasing, and the change trend is basically the same. Its changes may be affected by both natural and human factors.

(2) From 2000 to 2016, the spatial distribution of NPP in the main growing valleys of the southern slope of the Qilian Mountains is gradually increased from northwest to southeast, which shows the same characteristics as the spatial variation of altitude in the region.

(3) From 2000 to 2016, the spatial distribution of NPP and air temperature correlation coefficient of grassland in the main river valley of the southern slope of the Qilian Mountains basically shows a trend of increasing from northwest to southeast. However, the spatial distribution of the correlation coefficient between NPP and precipitation is opposite to that of the temperature, and its spatial distribution tends to gradually decrease from northwest to southeast.

\section{Fund project:}

National key research and development plan project (2017YFC0404304) ; Qinghai Natural Science Fund Project（2018-ZJ-903)

\section{References}

1. YUAN Wen-ping, CAI Wen-wen, LIU Dan, et al. Satellite-based Vegetation Production Models of
Terrestrial Ecosystem: An Overview [J]. Advances in Earth Science, 2014,29(05):541-550.

2. ZHAO Lu-qing. Spatio-temporal Patterns of the Vegetation Greenness Period and Net Primary Productivity and their Responses to Climate Change in the Middle and Lower Reaches of Yarlung Zangbo River [D]. East China Normal University (ECNU),2011.

3. Lieth H, Whittaker R H . Primary productivity of the biosphere [M]. Springer-Verlag, 1975.

4. SURI Gu-ga. Impact of Land Use Change on Net Primary Productivity in Hulunbeier Area [D]. Inner Mongolia Teaching University,2017.

5. Singh R P, Rovshan S, Goroshi S K, et al. Spatial and Temporal Variability of Net Primary Productivity (NPP) over Terrestrial Biosphere of India Using NOAA-AVHRR Based GloPEM Model [J]. Journal of the Indian Society of Remote Sensing, 2011, 39(3):345-353.

6. Potter C, Klooster S, Hiatt C, et al. Changes in the carbon cycle of Amazon ecosystems during the 2010 drought[J]. Environmental Research Letters, 2011, 6(3):034024.

7. ZHOU Xia-fei, YU Fang, CAO Guo-zhi, et al. Spatiotemporal Features of Carbon Source-Sink and Its Relationship with Climate Factors in QinghaiTibet Plateau Grassland Ecosystem During 20012015 [J]. Research of Soil and Water Conservation, 2019,26(01):76-81.

8. TIAN Zhi-hui, ZHANG Dan-dan, HE Xiao-hui, et al. Spatiotemporal Variations in Vegetation Net Primary Productivity and Their Driving Factors in Yellow River Basin from 2000 to 2015[J]. Research of Soil and Water Conservation, 2019,26(02):255-262.

9. YAN Jun-jie, LIU Hai-jun, ZHAO Yu, et al. Spatiotemporal Dynamics of Grassland Net Primary Productivity in Ili River Valley from 2000 to 2015[J]. Research of Soil and Water Conservation, 2018,25(05):390-396.

10. ZHAO Ting, ZHAO Wei, ZHANG Yi, et al. Dynamics of grassland net primary productivity and its relationship with climatic factors from 2001 to 2015 in northern China $[\mathrm{J}]$. Jiangsu Agricultural Sciences,2018,46(10):243-248.

11. GANG Cheng-cheng, WANG Zhao-qi, YANG Yue, et al. The NPP spatiotemporal variation of global grassland ecosystems in response to climate change over the past 100 years[J].Acta Prataculturae Sinica,2016,25(11):1-14.

12. LI Gang, ZHOU Lei, WANG Dao-long, et al. Variation of net primary productivity of Grassland and its response to climate in Inner Mongolia[J]. Ecology and Environmental Sciences, 2008,17(05):1948-1955

13. LIU Jie, MENG Bao-ping, GE Jing, et al. Spatiotemporal dynamic changes of grassland NPP in Gannan prefecture, as determined by the CASA model[J].Acta Prataculturae Sinica,2019,28(06):1932. 
14. HUANG Lu, ZHOU Wei, LI Jia-hui, et al. Analysis on spatial-temporal dynamics of different types grassland NPP and its climate influencing factors in Inner Mongolia [J]. Grassland and Turf, 2019,39(02):1-9.

15. YANG Han, ZHOU Wei, SHI Pei-qi, et al. Analysis of Temporal-Spatial Variations of NPP and Coupling Relationship with Hydrothermal Factors in Grasslands of Inner Mongolia[J]. Research of Soil and Water Conservation, 2019,26(02):234-240.

16. ZHOU Ping, WU Wei, WANG Rui, et al. Analysis of grassland simulation using different estimation models of grassland net primary productivity in China [J]. Pratacultural Science,2018,35(10):23812388.

17. ZHANG Mei-ling, CHEN Quan-gong, YAN Pei-jie. Spatio-temporal Distribution of Natural Grassland Net Primary Productivity in China[J]. Acta Agrestia Sinica,2018,26(05):1124-1131.

18. JIANG Rui-zhu, LI Xiu-qi, ZHU Yong-an, et al. Spatial-temporal variation of NPP and NDVI correlation in wetland of Yellow River Delta based on MODIS data[J]. Acta Ecologica Sinica,2011,31(22):6708-6716.

19. Steven W. Running Maosheng Zhao. User's Guide Daily GPP and Annual NPP (MOD17A2/A3) Products NASA Earth Observing System MODIS Land Algorithm http://www.ntsg.umt.edu/files/modis/MOD17UsersG uide2015_v3.pdf

20. SU Hui-min, GUO Hao,XIA Zhao-hua, et al. Dynamic Monitoring on Vegetation Coverage of Beijing Based on MODIS Data[J]. Soil and Water Conservation in China, 2019(02): 41-43, 55.

21. HAN Wang-ya, ZHANG Chao, ZENG Yuan, et al. Spatio-temporal changes and driving factors in the net primary productivity of Lhasa River Basin from 2000 to 2015[J]. Acta Ecologica Sinica, 2018, 38(24): 8787-8798.

22. LIN Zhi-dong, WU Guo-sheng. Spatial-temporal Changing Characteristics of NPP and NDVI Correlation in Junxi Valley, Datian County: A Study Based on MODIS [J]. Journal of Subtropical Resources and Environment, 2015, 10(01): 27-33.

23. LI Su-ying, CHANG Ying, WANG Xiu-mei, et al. Ecological Effect of Topography on Net Primary Productivity of the Typical Steppe [J]. Chinese Journal of Grassland, 2013,35(02):59-63.

24. ZHANG Yu-shun, JIA Wen-xiong, LIU Ya-rong, et al. $[\mathrm{J}]$. Response of net primary productivity to climatic factors in Qilian Mountains in resent eleven years [J]. Arid Land Geography, 2016,39(01):77-85.

25. SHI Xiao-liang, YANG Zhi-yong, WANG Xin-shuang, et al. Spatial and Temporal Variation of Net Primary Productivity and Its Relationship with Climate Factors in the Chinese Loess Plateau [J]. Chinese Journal of Agrometeorology, 2016, 37(04): 445-453. 